\title{
Entre antropología, estudios culturales y turismo: una propuesta de reflexividad disciplinar diacrónica
}

\author{
Gabriel Comparato* \\ Universidad Nacional de la Plata (Argentina)
}

\begin{abstract}
Resumen: El presente escrito constituye un análisis de segundo orden que relaciona diacrónicamente el campo de la antropología con el del turismo e incorpora, a modo de reflexión, las potencialidades epistémicas de los Estudios Culturales. Para ello se establece una hoja de ruta en función de las coordenadas que establecen dos momentos históricos-contextuales diferentes, aunque relacionados entre sí. Uno de ellos hace alusión al contexto de surgimiento de la antropología del turismo y, un segundo, propio de las últimas décadas del siglo XX que, pese su marginalidad, se caracterizará por la crítica al corazón antropológico: el concepto de cultura y su arbitrariedad. La propuesta tiene la particularidad de exponer discusiones ontológicas y epistemológicas en torno a la cultura y al turismo que no solo ofrece una lectura de tipo histórica sino también por poner en juego el sentido político que adquieren estos conceptos a la luz de tensiones disciplinares contemporáneas.
\end{abstract}

Palabras Clave: Turismo; Cultura; Antropología; Disciplina; Epistemología; Ontología; Historia.

Between anthropology, cultural studies and tourism: a proposal of diachronic disciplinary reflexivity

Abstract: The present paper constitutes a second order analysis that relates diachronically the field of anthropology with tourism and incorporates, by way of reflection, the epistemic potential of Cultural Studies. For this purpose, a roadmap is established based on the coordinates that display two different but interrelated historical-contextual moments. The first is when Anthropology of Tourism emerged as a subject matter in itself, and the second, typical of the last few decades of the twentieth century that, although marginal is insidious, that is the critics of the very concept of anthropology, based on culture and subjective perspectives.. The proposal highlights various ontological and epistemological debates relating to culture and tourism that have existed not only in time but also in politics, above all in academic interdisciplinary tensions.

Keywords: Tourism; Culture; Anthropology; Discipline; Epistemology; Ontology; History.

"Como dijo Thoreau, no vale la pena dar la vuelta al mundo para ir a contar los gatos que hay en Zansíbar"

(Geertz, 2003:29)

\section{Introducción}

El viaje, como práctica, adquiere múltiples sentidos y pone en juego, como pocos, las fronteras. Como concepto puede constituir una metáfora de posiciones ontológicas y epistemológicas muy variadas, desde las más herméticas y esquemáticas conclusiones, como es el hecho de contar gatos, hasta dinámicas hibridas y complejas interrelaciones. Así como la cultura está en los labios de todos (Brumann, 1999), con el turismo pareciera pasar algo similar. Adquieren un uso polivalente, con usos muy distantes uno de otros y con connotaciones pendulares. Se trata de conceptos, y hasta de campos, que no solo han

Instituto de Investigaciones en Turismo - Facultad de Ciencias Económicas, Universidad Nacional de la Plata, Argentina;

E-mail: gabrielcomparato@gmail.com 
ganado popularidad dentro del mundo académico, sino en diversos planos, incluyendo el desarrollo de políticas públicas o la gestión organizacional. Difícilmente se pueda separar al turismo, con su status de ser una de las principales actividades económicas del mundo, de la cultura, con su status de ser una de las tres palabras más complicadas del idioma inglés (Williams, 1976 citado en Wright, 2004:128).

Por tanto, son numerosos y divergentes los abordajes posibles que se deriven de analizar y relacionar la antropología con el turismo y, claro está, no es la intención agotarlos aquí. No obstante sí se considera necesario explorar un eje de investigación emergente dentro de la práctica turística que tiene que ver con un proceso de reflexividad disciplinar que se da al interior del mismo y que, como tal, incluye a otros campos. Ello implica, en este sentido, fortalecer el carácter trans-relacional y, con ello, evidenciar el carácter sinérgico y dialógico que pueden adquirir estos cuerpos de conocimientos, sin descuidar las diferencias y particularidades. Se sostiene, en efecto, una relación simbiótica, entendiendo que los debates antropológicos no solo pueden enriquecer y complejizar el abordaje teórico y empírico de los estudios en el turismo sino que, además, estos últimos pueden reorientar, complejizar las nuevas conceptualizaciones de los estudios culturales.

Para ello, metodológicamente se procedió a realizar una revisión y análisis bibliográfico en virtud de relacionar cualitativamente el campo antropológico con el turístico y, con ello, diseñar una hoja de ruta a partir de las coordenadas de dos momentos históricos-contextuales diferentes, aunque estrechamente relacionados entre sí. Se trata de contextos epocales que presentan la particularidad de exponer discusiones ontológicas y epistemológicas en torno a la cultura y al turismo con denominadores comunes pero también, en cierta medida, con posicionamientos cruzados. El primer encuadre, que se podría denominar "esencial-nostálgico", hace alusión al contexto de surgimiento de la antropología del turismo y combina, por un lado, cierto pesimismo intelectual frente a los impactos culturales de la actividad y, por otro, el surgimiento del "giro interpretativo" y semiótico para entender la cultura. Por su parte, el segundo momento, a diferencia, tendrá lugar fundamentalmente durante el final del siglo XX (aunque con raíces que lo anteceden) y se caracterizará por la crítica al corazón antropológico: el concepto de cultura y su arbitrariedad. Los estudios en turismo para este entonces, pese a su marginalidad general, tendrán mayores niveles de consolidación e institucionalización que décadas atrás y, además, empezarán a poner en discusión nuevas formulaciones del concepto de poder y su capacidad de definir y redefinir fronteras.

Serán estos dos momentos históricos-contextuales los que permitirán incorporar un tercer apartado de corte reflexivo que incorporará las tensiones ontológicas y epistemológicas que han puesto en la escena del debate de los Estudios Culturales y mediante los cuales se han diferenciado de la antropología clásica. Esto no solo permitirá recuperar algunas tensiones teóricas descritas en los procesos históricos seleccionados sino, sobre todo, abrir juego a las potencialidades epistémicas en virtud de relacionar los estudios culturales con los turísticos. Lo que se pone en juego, en este contexto, es el sentido político que adquieren tanto la cultura como el turismo a partir de coordenadas temporales y espaciales diferentes. La fluidez, dinamismo y la hibridación empezarán a tener forma y lugar.

\section{Escribiendo sobre cultura y contra turismo}

En virtud de lo anterior, y siguiendo el orden propuesto al inicio, el presente ensayo pretende abordar dos ejes de análisis. Por una parte, incluye una contextualización histórica de manera de identificar, a modo general, los debates que tienen lugar en el centro de estos campos bajo dos momentos determinados. Se entiende, en este sentido, que esos dos momentos responden a grados de avances diferenciales en lo que refiere a la antropología del turismo y, al mismo tiempo, periodos donde el concepto cultura es puesto en discusión bajo distintos parámetros. Para ello, se toma como referencia un primer momento de análisis que responde al contexto en el que Geertz realizaba un "giro interpretativo" del análisis cultural y que es, al mismo tiempo, el contexto epocal en el que empiezan a surgir los primeros estudios antropológicos en turismo. Se trata, en efecto, de un momento iniciático de la antropología del turismo que se caracterizó por una tendencia a analizar los efectos irreversibles que la práctica turística estaba produciendo o, en su carácter potencial, las amenazas que este puede ocasionar. Por otro, se complementará con un segundo momento o contexto epocal, asociado a la última década del siglo XX, donde la antropología del turismo, pese a mantener cierta marginalidad, se empezará a consolidar y donde reorientará las investigaciones a nuevos ejes de análisis. Para dicho entonces, los estudios culturales, a partir de la consolidación de corrientes críticas gestadas décadas atrás, no solo serán más diversos sino que pondrán en tela de discusión el mismo concepto de cultura y la arbitrariedad que acarrea la diferenciación entre "otros" culturales. 
Cabe especificar, además, que estos momentos no constituirán teorías particulares claramente diferenciables sino tendencias epistemológicas y ontológicas con ciertos denominadores comunes. Es decir, a los efectos de no recaer en un reduccionismo analítico el presente trabajo opta por plantear una lógica procesual y tendencial en la medida que ambas poseen algunos antecedentes que les preceden, que se caracterizan por heterogeneidad interna, que no se excluyen el uno con el otro y, menos que menos, están caducos. Por el contrario, se plantea que dichos tendencias constituyen puntos de inicio estimular ejercicios de reflexividad disciplinar y bajo ningún punto, constituyen cierres. Es decir, constituyen disparadores para poner en dialogo los Estudios Culturales con los Turísticos y proponen un camino para la deconstrucción científica.

De esta manera, el primer momento propuesto tiene lugar luego de la segunda mitad del siglo XX. Según Ortner (1999), Clifford Geertz fue uno de los antropólogos más destacados y una de las figuras más importantes en la reconfiguración de los límites entre humanidades y ciencias sociales de la segunda mitad del siglo XX a partir de su "giro interpretativo" con un estilo literario y constructivista. Contribuyó a partir de las décadas de los '60 y '70 a formular un enfoque específicamente cultural de la subjetividad y de su teoría pueden señalarse dos dimensiones o vertientes (Ortner, 2005). Por un lado, un concepto ligado a la tradición norteamericana que ha sido flanco de diversas críticas, en donde la cultura es definida como la visión del mundo y el ethos de un grupo particular. Es decir, la idea de que los grupos tienen culturas específicas, compartidas por todos sus miembros, con presencia de homogeneidad y falta de diferenciación al interior al interior. Pero, por otro, una teoría filosófica literaria del proceso cultural que hace hincapié en la construcción del sentido y las subjetividades a través de procesos simbólicos. Desde este último marco analítico, Geertz (2003) en "La interpretación de las culturas" de 1973, se distancia de conceptos de cultura en tanto modo total de vida de un grupo, para posicionar un concepto fundamentalmente semiótico. Su posicionamiento epistemológico, en este sentido, es que el análisis de la cultura no tiene que ser una ciencia experimental en busca de leyes, sino una ciencia interpretativa en busca de las tramas y redes de significaciones. La cultura, por tanto, no es una entidad sino un contexto y debe ser entendida como un sistema en interacción de signos interpretables. Para ello, y a los efectos de referirse al trabajo etnográfico, diferencia una descripción superficial de una descripción densa. Mientras que la primera, por más exhaustiva que sea, busca enunciar un conjunto de conductas y experiencias, la descripción densa persigue definir una jerarquía estratificada de estructuras significativas. Por tanto, el análisis consiste en desentrañar y descifrar dichas tramas a partir de un ejercicio de segundo o tercer orden considerando a tales estructuras como múltiples, complejas, superpuestas, extrañas, irregulares y no explícitas. En este marco, frente la distinción entre descripción y explicación que ha caracterizado a las ciencias sociales, el autor sostiene que este caso se da con una distinción aún más relativa, entre inscripción (descripción densa) y especificación (diagnóstico), entre establecer la significación que tienen para sus atores y enunciar lo que el conocimiento muestra sobre la sociedad al que se refiere. Geertz expresa:

"Pequeños hechos hablan de grandes cuestiones, guiños hablan de epistemología o correrías contra ovejas hablan de revolución, porque están hechos para hacerlo asî”(Geertz, 2003:35).

En este contexto epocal, existieron al menos dos tendencias que se manifestaban en el abordaje de la cultura por parte de los constructos teóricos del turismo. La primera está asociada al abordaje estrictamente antropológico del turismo y la segunda a la cultura como espacio de convergencia de saberes y disciplinas diversas. Desde este último eje, se puede afirmar que a partir de la década de los '70 crecieron y se consolidaron los estudios turísticos que hacían hincapié en los impactos negativos que la actividad estaba ocasionando en geografías muy distintas, especialmente en los destinos de sol y playa donde el turismo de masas había tenido epicentro décadas atrás. Esta plataforma de análisis, denominada como "precautoria" según Jafari (2005), se consolida en tanto que la comunidad científica interpreta que los problemas generados por la práctica turística no solo están vinculados con la cultura y contexto ecológico receptor, sino incluso en los supuestos beneficios económicos. A modo de ejemplo, así como el turismo puede generar divisas y constituir un motor de crecimiento, también puede ocasionar, como correlato, procesos de concentración y segregación económica. O, así como el turismo puede generar empleo, este puede ser mayormente estacional, precarizado o de baja cualificación. Estos debates no serán menores sino que, por el contrario, pondrá en discusión gran parte de la producción bibliográfica en turismo que hasta entonces se tenía una génesis disciplinar por parte de la economía, y en menor medida, de la geografía. 
En virtud de lo anterior, la cultura no solo fue abordada en el marco de la actividad turística por antropólogos, sino por múltiples disciplinas y tendrá su consolidación durante las últimas décadas del siglo XX. El común denominador que predominó, no obstante, es una idea de cultura entendida como "producto" con una connotación "culturalista", entendiendo que son dichos rasgos culturales constituyen genuinos recursos turísticos que requieren ser puestos en valor. Es decir, la dimensión ontológica estará asociada a los viejos significados de cultura donde esta representa la totalidad de estilos de vida de un grupo, incluyendo conocimiento, creencias, arte, etc. y donde dichas características son representativas del multiculturalismo, y en efecto, son las que dan origen a modalidades diversas de turismo cultural. Pese a la diversidad teórica, los posicionamientos compartían la idea de un mundo formado por pueblos, donde cada pueblo se equipara con una cultura, cada uno con estilos de vida coherentes y posibles de ser delineados a partir de una lista de rasgos característicos. Más precisamente, se caracterizaron por presentar una delimitación geográfica específica, autoreproducidas, con homogenidad interna y un sistema subyacente de significados compartidos auténticos (Wright, 1999). Se podría agregar, asimismo, que estos abordajes tendrán su consolidación dentro del escenario institucional internacional sobre todo a partir de las declaraciones de valor universal excepcional que adquirieron ciertos bienes patrimoniales principalmente a partir de la década del ' 80 y de los '90. Desde el punto de vista discursivo, ya no solo se empezó a considerar las amenazas que el turismo puede acarrear para la conservación y protección del patrimonio, sino también de sus múltiples potencialidades asociadas a poner en valor las características más distintivas de diversos grupos sociales, así como rescatar aquellas que están siendo amenazadas, el fomento a la interculturalidad, la paz y la comunicación mundial, etc.

La antropología del turismo para los '70, en cambio, aún era incipiente, y más en el contexto sudamericano (Santana-Talavera, 2015). No obstante, si hay un elemento que tendrá un impacto en la producción de la literatura europea y norteamericana de esos años (y en los que le continuarán) es que dichos trabajos inaugurarán una tradición asociada a investigar los impactos de la actividad turística. Pero desde este marco disciplinar no se analizará cualquier tipo de impacto, ni en cualquier componente de la práctica turística sino, particularmente, en los que refiere a las comunidades receptoras, especialmente en pequeños poblados ubicados en países periféricos o con alguna posición subordinada y, además, con un especial énfasis en los proceso de aculturación. La preocupación de la antropología por el turismo se centrará, en efecto, en la degradación social y cultural de ciertas comunidades a partir de la presencia de valores y prácticas exógenas modernizadoras portadas principalmente por los turistas (dos Santos, 2005). Es decir, este paradigma anfitrión-invitado estará centrado en los peligros y amenazas que refiere el turismo para las comunidades que constituyen anfitriones. De ahí que se discuta y critique el abordaje "nostálgico" en el que ha utilizado las experiencias turísticas para mercantilizar o exotizar referentes identitarios de un grupo particular (Pereiro, 2013).

Asimismo, el contexto latinoamericano presentará sus particularidades en términos analíticos. Más precisamente, y a los efectos de caracterizar cómo se han comportado los análisis de la antropología en turismo en los países en desarrollo, Salazar (2006) destaca un primer momento relacionado a la década de los '70 y '80. Sostiene que esta antropología mantuvo una escala de análisis predominante macro, donde la cultura estará estrechamente relacionada a la economía política, a la dependencia y al neocolonialismo. Dado este marco, y con influencia marxista, se personifica el poder a partir de la hegemonía de las naciones desarrolladas y de las corporaciones transnacionales y es desde allí donde se destacan los desiguales impactos económicos y sociales asociados con el turismo. En este debate, se incluía la preguntas tales como si el turismo era o no funcional al colonialismo y si era posible entenderlo en un contexto más amplio tal la desigualdades entre centros y periferias. Por su parte, durante la última década del siglo XX, se consolida una plataforma de conocimientos asociado al turismo alternativo y sostenible. Es decir, aquellas formas y modalidades turísticas que buscan un equilibrio entre las dimensiones naturales, socioculturales y económicas de todo proceso de desarrollo y que fomentan interacciones positivas entre anfitriones e invitados. Los debates, dado este marco, se centrarán en la discusión en torno al concepto de "autenticidad", identificando los problemas que se pueden originar a partir de asignarle un valor monetario a las prácticas sociales y culturales de un territorio (mercantilización cultura). El quid del debate se empezará a enfocar en el poder comunicativo del turismo y, en consecuencia, el poder performativo de la representación. Por su parte, se podría destacar una tercera línea de abordaje, no necesariamente posterior al anterior, que tuvo especial interés para los antropólogos. Desde este enfoque, el problema del actor estará posicionado desde el "microcosmos" en función del contacto e interacción entre "otros" culturales. Este abordaje introdujo y enriqueció el debate a partir de otras nociones de poder a la hora de entender la relación asimétrica que caracteriza, en general, al contacto entre el invitado y anfitrión. 
Gabriela Coronado (2015), en este punto, incorporaría un grupo de trabajos que posicionan al turismo como una estrategia poscolonialista, de donde se sostiene que los actores culturales constituyen el foco de la fascinación como otredad y en consecuencia como una atracción turística. Las imágenes estereotipadas, como primitivos exóticos, constituyen el imaginario que el turismo promoverá y, a la vez, el producto que se ofrecerá para satisfacer su búsqueda nostálgica de ciertos pasados. Bajo este prisma analítico, el turismo constituye un agente que actúa en el control de las representaciones.

A los efectos de deconstruir la idea de cultura que caracterizó ontológicamente a este contexto se pueden tomar como referencias los aportes de Chirstoph Brumman en "Writting for culture"(1999). Más concretamente, sostiene que la visión tradicional de cultura sugiere límites, homogeneidad, estabilidad y coherencia. Es decir, la cultura posicionada desde un lugar que implica una totalidad de estilos de vida de un grupo, con formas y patrones reiterados de pensar, sentir y actuar. Es decir, que pese a que coexistirán diversidad de definiciones dentro de la literatura especializada, la mayoría mantendrá dicha impronta siendo que el factor que variará, en general, es si cultura es considerada como una suma, un conjunto, un sistema, una clase, una organización o, incluyendo metáforas o concepciones organicistas, "un cuerpo". Es decir, la cultura por ejemplo, como el cuerpo de creencias, comportamiento, conocimientos, sanciones valores y objetivos que marcan o caracterizan la vida de vida de una sociedad.

\section{Escribiendo contra cultura y sobre turismo}

El segundo momento descrito no necesariamente se expresa dentro del campo turístico como una ruptura sino que, por un lado, como una tendencia a la diversificación de contenidos y unidades de análisis, provengan o no del campo estrictamente antropológico, y, por otro, por la incorporación y re-configuración de ciertos conceptos y fronteras. Es decir este momento o periodo que se vislumbra a partir de los '90, no se explica sin la progresiva consolidación e institucionalización que fue adquiriendo el turismo como campo disciplinar. Pero, claro está, demostrará ciertas características diferenciales, como la disposición y utilización del concepto de poder bajo argumentaciones y abordajes no tradicionales. Enfoques que, por ejemplo, se diferenciarán de los análisis materialistas más característicos de la teoría liberal económica (o incluso a la crítica marxista de décadas atrás) y la profundización de otras escalas analíticas, tales como los niveles micro.

El primer punto a señalar es, entonces, que los antropólogos no abandonan cierto pesimismo intelectual y empírico sobre los impactos del turismo sino que dicha discusión estará matizada a partir incorporar otras unidades de análisis o, al mismo tiempo, otras dimensiones o posicionamientos epistemológicos. En este sentido, por ejemplo, frente al modelo de aculturación, con énfasis en los impactos causa-efecto, Barreto (2007) y Pereiro (2013) proponen nuevos debates contemporáneos con centro en el cosmopolitismo y el hibridismo cultural. El turismo, en este marco, se lo abordará como como actividad y/o como discurso ambivalente. Es una actividad, porque tal como se enfocó la antropología del turismo de los '70, implica procesos de movilidad entre sujetos sociales y, como tales, conlleva impactos. Pero, además, constituye una formación discursiva. En este sentido, lo que se pondrá en discusión es justamente el enfoque nostálgico y esencialista que caracterizó al abordaje cultural en turismo de décadas atrás, mediante el cual se argumentaba que esta actividad difunde imágenes y significados de diferentes culturas. Por el contrario, se posiciona a la práctica turística, y sus múltiples agentes, como modificadores y productores de nuevos significados. Este marco de análisis que se vislumbra más fuertemente a partir de los últimos años del siglo XX, permite reflexionar sobre el carácter performativo de la práctica turística y, con ello, abre nuevas formas de interpretar el poder, el conflicto y las fronteras. La práctica, como tal, no es ni inerte ni inocente, sino que es selectiva y productora.

Salazar (2013), en esta línea, sostiene que el papel de la antropología como disciplina académica que crea los imaginarios del turismo en todo el mundo es más amplio de lo que generalmente se reconoce. A partir de analizar investigación etnográfica en Indonesia y Tanzania relata que los antropólogos han sido partidarios consecuentes de la gran narrativa nostálgica y que constituye un factor motivador para muchas actividades turísticas.

Barreto y Otamendi (2015), en su análisis bibliográfico de la antropología y turismo en los países de Argentina y Uruguay, sostienen que los estudios en esas latitudes comenzaron más fuertemente alrededor los 90'. Específicamente, destacan que a partir de ese contexto el interés etnográfico de los investigadores sobre los distintos aspectos del turismo se ha incrementado sustancialmente, donde identifican la inexistencia de un único paradigma teórico para analizar los casos etnográficos, sino que por el contrario, una "peculiar diversidad". Tal es así, que diferencian estudios empíricos vinculados 
al turismo y los pueblos originarios, al patrimonio, a las representaciones sociales, a la naturaleza y a la relación entre turismo y comunidad. La peculiaridad, según estos autores, es que la matriz crítica de los estudios no recae necesariamente en el lugar común de la valoración negativa o pesimista de la actividad, sino que la asocian a lo que Jafari (1994) llamaría la plataforma científica.

Por su parte, Roque Pinto (2015) si bien reconoce un crecimiento cuantitativo y cualitativo para la antropología turística en Brasil, vista en la multiplicación de los centros de formación, la consolidación de revistas científicas, la organización de eventos internacionales y el surgimiento de grupos de investigación multidisciplinarios, identifican un "gap" entre la relevancia económica-cultural de la actividad y su respectivo interés académico. Y ello se vislumbra, según el autor, al momento de contemplar áreas de financiamiento y en el "locus" investigativo que este ocupa. Plantea una marginalidad que se expresa en estudios muchas veces restringidos a un espacio mínimo o diluidos en análisis sobre religión o etnicidad.

Ahora bien, bajo los nuevos enfoques se considera que el turismo puede constituir una poderosa fuerza que fomente el contacto entre "otros" culturales, en un marco de relaciones interétnicas atravesando fronteras, divulgando, recreando y también generando nuevas imágenes e, incluso, incidir en la redefinición de los limites culturales (Pereiro, 2013). Es decir, el turismo se insertaría en lo que Stuart Hall (2010) denomina como "el espectáculo del otro" en tanto práctica representacional. Desde este lugar, el turismo en tanto actividad y discurso tipifica, clasifica, ordena y, a la vez, es un agente que puede, bajo formas diferentes y en distinta medida, generar estereotipos. Estereotipar, según el autor, implica reducir a ciertos grupos sociales a unos pocos rasgos esenciales y fijos. En este sentido, es común encontrar abordajes en este periodo que hacen eco de los riegos mercantilizadores del turismo, en tanto que reduce a una persona o sociedad a ciertos rasgos, los exagera y simplifica y los fijas sin cambio. Tiene, como consecuencia, una práctica de "cerradura" en tanto que simbólicamente fija límites y excluye todo lo que no pertenece. Esto tiende a ocurrir, o acentuarse, en sociedades con grandes desigualdades de poder. En otras palabras, existe un estrecho vínculo entre representación, diferencia y poder. Poder que desde un enfoque foucaultiano no estará definido exclusivamente por coerción sino también en términos de poder de la representación, de marcar, asignar y clasificar. El poder no solamente constriñe sino también es productivo, en tanto que produce nuevos discursos, nuevos conocimientos, prácticas e instituciones. Y, a la vez, no solo se vislumbra en términos macro, como se centró la antropología latinoamericana durante el momento inciático, sino también en la "micro físifica" del poder.

Lo que dirán diversos autores de este contexto epocal es que pese a los aportes constructivistas e interpretativos que realizó Geertz, el enfoque más tradicional de la cultura descuidó un aspecto esencial: las relaciones de poder (Ortner, 1999). Desde la misma teoría critica de Raymond Williams es que se insiste en que el proceso cultural se aprehende como un sistema cultural, con rasgos dominantes definidos por hegemonía. Pero que, también, por más eficaz que sea dicha dominación nunca es suficiente en tanto que existen contracorrientes en cualquier formación cultural. Es decir, formaciones culturales alternativas, residuales y emergentes. Dicho planteo permite plantear interrogantes en torno a la configuración cultural de las subjetividades de un mundo de relaciones de poder desiguales (Ortner, 2005).

Uno de los primeros autores en discutir la idea de que los grupos comparten esencialmente una cultura común, que son al mismo tiempo grupos discretos de individuos fue Frederik Barth. Critica, como tal, que (1976:12), la “(...) historia ha producido un mundo de pueblos separados con sus respectivas culturas y organizadas en una sociedad que, legítimamente, puede ser aislada para su descripción como si fuese una isla”. Por tanto, agrega que la constitución de los grupos étnicos y la naturaleza de los límites entre estos no han sido investigadas de la forma correspondiente. Es decir, los conceptos demasiado abstractos de "sociedad" que procurado gran parte de la antropología quedan sin examinar las características y los límites empíricos de los grupos. En efecto, aún subsiste la idea del aislamiento geográfico y social como conservador de la diversidad cultural. Por el contrario, el autor argumenta que las distinciones no dependen de la ausencia de interacción, sino que generalmente son el fundamento mismo. Por tanto, las diferencias culturales pueden persistir a pesar del contacto interétnico y de la interdependencia (Ob. Cit.).

Bruman, sin referirse al turismo, dice (1999:S5):

"These assumptions include the existence of a mosaic of territorially bounded, discrete cultures of which the world supposedly consists; the irrelevance of intra and interindividual variation the timelessness of the culture under the study..."

Por tanto, frente a la clásica visión que establece homogeneidad, coherencia y estabilidad, la concepción del análisis cultural se centrará, en este contexto, a poner en discusión en la idea de proceso a 
partir de incorporar inconsistencias, conflictos, contradicciones y cambios. Las identidades culturales no son inherentes y estáticas, sino dinámicas, fluidas y construidas situacionalmente en tiempos y lugares particulares. Existen identidades múltiples negociadas constantemente. Esto lleva a poner de manifiesto y en discusión la idea límites. Este acto de identificar culturas discretas termina siendo, para la crítica contemporánea, empíricamente infundado, teóricamente confuso y moralmente inaceptable (Brumann, 1999). Por otra parte, la corriente crítica de la tradición clásica empieza a diferenciarse conceptualmente de aquellos que asociaban la idea de cultura geográficamente delimitada (en el sentido físico) para estudiar formaciones complejas, caracterizadas no solo por vínculos locales o nacionales, sino también trasnacionales, con discursos discontinuos e identidades hibridizadas. El foco, no son necesariamente las características compartidas, sino los puntos de contactos, los límites, las zonas de fricción, sus intersticios. Pero Hall (2000) no interpretará dichos cambios simplemente en términos de avances progresivos y graduales del conocimiento científico sino a partir del ruido teórico generado por al menos dos interrupciones: el feminismo y la relectura de la raza. Estas corrientes dieron lugar, según Stuart, a la expansión radical de la noción de poder que hasta entonces se circunscribía en general al dominio de lo público y además reabrieron la frontera entre la teoría social y la teoría psicoanalítica.

La crítica exige un análisis más elocuente en términos de la política implícita en el uso del concepto de cultura. Es decir, donde por un lado se reconoce el peligro de "la cultura" cuando se pone en juego para esencializar y demonizar grupos enteros de personas y, además, por su valor político crítico en tanto permite analizar el funcionamiento del poder y quienes carecen de él (Ortner, 2005). Sobre todo si se considera el desarrollo del turismo indígena (Xerardo Pereiro, 2013) que tradicionalmente acentúa los aspectos culturales tradicionales y nativistas, pero no los contemporáneos, creando una imagen idealizada de sus modos de vivir, y al mismo tiempo estatizándolos bajo estereotipos. Retomando a Hall (2010), y su relación con una reflexión turística, en esta instancia se agrega entonces que estereotipar tiene su propia poética (sus propias formas de funcionamiento) y su política (el investimento del poder).

No obstante y pese a existir acuerdos generales, este periodo se caracterizará, además, por consolidar un proceso de crítica hacia el corazón de los estudios culturales: el concepto de cultura en base a una contra cultura. Lila Abu-Lughod en "Writing against culture" (1991) y en referencia al estudio de premisas feministas y de los halfies, pone en juego las etnografías de lo particular. Sostiene que estas etnografías se caracterizaron por estar relativamente ausentes en los análisis antropológicos tradicionales y que su importancia radica en interpelar la distinción entre el "yo" y un "otro" y, como tal, en reflexionar sobre los efectos políticos de esta distinción. Más concretamente estos abordajes interpelan con crudeza los supuestos problemas y conceptos de la antropología. Su tesis se basa en que el análisis cultural conlleva jerarquía y que, por tanto, opera para validar las separaciones e incluso para reforzar desigualdades. Es decir, la antropología por un lado explica con el fin de responder y entender las diferencias culturales pero, al mismo tiempo, también ayuda a construirla, producirla y mantenerla (Abu-Lughod, 1991). Con perspicacia pregunta:

"What happens when the "other" that the antropologist is studying is simultaneously constructed as, al least partially, a self?” (Ob. Cit.:468)

Si bien compartirá con otros autores su crítica a la cultura en términos discretos y coherentes y consensuales, se diferenciará al sostener que pese de los esfuerzos antiesencialistas, el concepto de cultura mantiene la tendencia a congelar las diferencias. Agrega que la antropología dedica un esfuerzo sobredeterminado para producir descripciones etnográficas de creencias o acciones de las personas y se tiende a restar importancia a las contradicciones, a los conflictos de intereses, a las motivaciones y circunstancias cambiantes. La supresión del tiempo y del conflicto hacen de lo que está dentro del límite establecido por la homogeneización sea algo fijo y esencial. En este marco, la construcción feminista parte de un proceso de construcción del "yo" diametralmente opuesto del antropólogo en tanto parte de una conciencia de opresión de un "otro" (Ob. Cit.).

Lo anterior lleva a pensar en la articulación política que adquiere el concepto de cultura. Susan Wright (2004) sostiene, en este marco, que ya sea porque los conceptos estén siendo desplegados directamente por antropólogos o que las ideas estén siendo atribuidas a la antropología para su legitimación, en todos los casos está implicada la politización del término cultura. Es decir, la cultura no es solo un dominio específico de la vida (como economía) sino que es constructora, constitutiva de todos los aspectos de esta (incluyendo la economía). La cultura, como tal es disputada, y tiene al menos tres momentos para la construcción de significado. El primero corresponde a las estrategias por parte de agentes específicos 
para redefinir los símbolos que ofrecen una visión del mundo y, en definitiva, de cómo debería ser o comportarse la gente. Posteriormente, un momento que se vislumbra en "cómo" y "cuándo" dicha ideología se institucionaliza y, por tanto, que no requiere de agentes específicos. Y, tercero, cómo esos términos claves entran en otros dominios como la vida cotidiana.

Estas conceptualizaciones abren nuevos terrenos para el turismo. La visión sistémica funcional que predominaba en los análisis científicos actuales dentro de este campo (y que aún lo caracterizan) mantienen la idea de coherencia dentro de los procesos sociales. En este marco, las teorías antropológicas contribuyen a poner en juego el poder no solo en términos de hegemonía, como Gramsci, sino en términos más amplios y en la vinculación poder/saber, a partir de las contribuciones de poder en términos relacionales de Foucault, y la desigualdad que caracteriza al campo, como Bourdieu. Desde este lugar, entonces, la cultura para el turismo no solo adquiere un uso económico en términos de atractividad o producto turístico sino también político. El turismo constituye un medio (y un escenario) mediante el cual se politiza de la cultura, generando formaciones discursivas frente a diversos grupos sociales con intereses heterogéneos.

Actualmente, ya son diversos los antropólogos que han tomado distancia a las posiciones que tienden a esencializar a las culturas al suponer que existe una versión real o auténtica que el turismo dañaría. La idea de la mercantilización cultural se funda en la creencia de que el turismo genera una pérdida de autenticidad y significación culturales (Salazar, 2006). La autenticidad, dado este nuevo planteamiento, estará puesta en discusión en términos de la arbitrariedad que acarrea. Los significados esenciales son discursos que algunas personas tenían autoridad de hacerlos autoritarios y por lo tanto el análisis consiste en interpelar cómo un discurso autorizado es producido. Asad (1979 citado en Wright, 2004:130) afirma que los antropólogos definieron equivocadamente como cultura autentica ideologías dominantes históricamente especificas o discursos autorizados. Si la mirada del turista tienen realmente el poder de actuar y transformar la identidad de las personas contempladas; entonces, el turismo tiene tanto potencial de revivir antiguos valores como de destruirlos (Salazar, 2006).

El turismo, por tanto, también abre posibilidades de valorizar elementos o prácticas culturales que, por distintas razones y circunstancias, fueron históricamente desvalorizadas o desprestigiadas. Y, con ello, se abre la posibilidad de generar escenarios multifacéticos de la cultura, como la puesta en valor de subculturas históricamente desterritorializadas o deslegitimadas. Es decir, construcciones en reconstrucción y producción permanente, pero no por eso desligadas de las formas diferentes de expresión del poder.

\section{Tensiones disciplinares contemporáneas}

Ahora bien, plantear estas analogías diacrónicas no solo adquiere importancia desde el punto de vista ontológico sino también por permitir reflexionar, en términos más generales, de ciertas tensiones actuales que vislumbran a nivel de "campo" o de forma "disciplinar". En este sentido, si se toman las aportaciones de Hall (1992), se podría hacer cierta analogía en términos del "ruido teórico" que caracterizan a los Estudios Culturales y Turísticos. Según este autor, los Estudios Culturales representan un conjunto de formaciones inestables que se caracterizan por ser abordadas por diversos autores con heterogéneas trayectorias y que se manifiestan en diferentes metodologías y posiciones teóricas, todas en disputa. Y si hay un elemento que convive también dentro del estudio de la práctica turística es el carácter tensional que hace hincapié Hall en ese escrito. En este sentido, se podría afirmar que convive con una tensión entre la negativa de cerrar el campo, delimitarlo, controlarlo y, a la vez, otra que tiende a la apertura y argumentación de posiciones. Se podría agregar, incluso, que así como los estudios culturales son notoriamente difíciles de definir debido a su extenso alcance y por las transformaciones que ha tenido en virtud de los cruces geográficos y geopolíticos (Ortner, 1999) los estudios turísticos manifiestan también una dispersión disciplinar. Es decir, donde el conocimiento es diverso, ecléctico y heterogéneo, y donde numerosos trabajos traspolan conceptos utilizados en otras ciencias o disciplinas, a veces de manera descontextualiza de las teorías que le dieron origen, generando una predominancia de enfoques interdisciplinares y no tanto así en un ejercicio transdisciplinar (Comparato, 2017).

Por otra parte, siguiendo a Ortiz (2004) los estudios culturales (y podríamos agregar los turísticos) se inscriben en un proceso de renovación de las ciencias sociales donde caracterizan por su dimensión multidisciplinaria, incluso por la interpelación a las fronteras tradicionales establecidas en los departamentos y universidades. Con especificidades distintas, los estudios turísticos manifiestan similitudes y pese a su menor nivel de consolidación, encuentra su potencial cuando se articulan relacionalmente a 
partir de diferentes aportes disciplinares, como economía, sociología, antropología, geografía, psicología, etc. De hecho, su proceso de institucionalización también es tardío y heterogéneo para América Latina (post-regreso a la democracia), no solo por los contenidos curriculares de formación sino en el marco institucional-disciplinar en el cual se insertarán. En esta línea, ambos campos representan encrucijadas y puntos de convergencia de movimientos y ritmos diferenciados, con desafíos transdiciplinares y constituyen un “(...) punto de partida para un "viaje" entre saberes compartimentados"(Ob. Cit.:195).

El punto es que los Estudios Culturales, como tales, no constituyen una entidad homogénea, sino que por el contrario presentan una gran controversia y polémica interna y externa, que incluye desde su nombre, sus características, sus objetivos, sus orígenes y que se complejiza, especialmente, al poner en diálogo estas perspectivas dentro del contexto del pensamiento crítico latinoamericano (Pagés, 2012). Si bien no es objeto de este trabajo analizar en profundidad este punto, interesa resaltar algunas premisas claves. En este sentido, Restrepo en su libro "Antropología y estudios culturales: disputas y confluencias desde la periferia" (2012) refiere a los estudios culturales como el campo transdisciplinario constituido por las prácticas intelectuales para comprender e intervenir, desde un enfoque contextual, en cierto tipo de articulaciones concretas entre lo cultural y lo político. Y señala un conjunto de rasgos que considera centrales, que hacen a la especificidad del campo y que prestan mayor consenso dentro de la literatura. Estos estudios se caracterizarían: i) por la problemática, en la medida que imbrican lo cultural y las relaciones de poder y, por tanto, la cultura responde a una problemática definida por su articulación constitutiva con el poder y la representación. En este marco, sostiene que la antropología ha pensado la cultura principalmente como diferencia, mientras que los estudios culturales lo han hecho como desigualdad; ii) por su enfoque transdisciplinario e indisciplinado, en tanto que reacciona a los reduccionismos que buscan explicar sólo desde una dimensión o clivaje particular. La propuesta no implica una mera yuxtaposición mecánica de dos o más disciplinas sino entender que las explicaciones de la cultura no se circunscriben a lo intrínsecamente cultural (corno tienden a hacer cierta antropología), sino que incorporan exterioridades, corno las relaciones sociales, el poder o la economía; iii) por su vocación política en el sentido de que lo que se busca con los estudios culturales no es simplemente producir mejor teoría para acumular conocimiento, sino que es un saber para intervenir en el mundo, para desatar relaciones de explotación, dominación y sujeción culturalmente articuladas (expresado en la famosa frase "politización de lo teórico y teorización de lo político"); y finalmente iv) la apelación al contextualismo. Es decir la referencia al contexto como un aspecto central al momento de todo abordaje. Pero aclara que ello no implica una simple identificación de escalas sino de articulaciones significantes y de relaciones de poder. Los Estudios Culturales se caracterizarán por proponer, ante todo, un tipo de pensamiento relacional que argumenta que cualquier práctica, evento o representación existe en una red de relaciones.

Pagés, (2012), en este marco, agregará que los Estudios Culturales no pueden ser definidos exclusivamente por los temas de investigación ni por las metodologías utilizadas, pero sí por la construcción epistemológica de estos temas, reenfocando la mirada desde las fronteras, los bordes y las áreas grises. Es en este sentido, para Valencia (2011) la cultura deja de ser un objeto estático y pasa a entenderse como un escenario de tensiones, de confrontación y conflicto, pero también de diálogo y negociación. Como tal, resulta clave por su articulación política a través de dispositivos de poder concretos y por mostrar, tal como señala Follari (2003) que la cuestión de la identidad colectiva no debe pensarse "esencialistamente". La identidad se hace, cambia, se construye y deconstruye permanentemente; ésta es una constatación con fuertes efectos en el pensamiento de lo cultural y de lo político.

Los Estudios Culturales en América Latina, pese a tener raíces que le anteceden, han tenido un auge sumamente acentuado sobre todo a finales del siglo XX y constituyen un campo joven. Follari (2003), planteará esta cuestión como una "inesperada madurez", en la medida que ha tenido un "vigoroso desarrollo y su fuerte asentamiento en muy diversos espacios de reflexión y de discusión”. No obstante, autores como Pagés (2012) aclararán que si bien se entiende la inserción al continente como un proceso mayor que se dio a escala global, no puede considerarse simplemente una subdivisión o una rama de los estudios culturales británicos o norteamericanos. Por el contrario, que debe comprenderse ciertas articulaciones o presupuestos que ya estaban presentes en otras tradiciones criticas anteriores. Se podría agregar, incluso, que pese a dicho crecimiento pronunciado dentro de la región y las potencialidades epistémicas que exponen, resulta aún incipiente su utilización o aplicación dentro de los estudios turísticos.

Por su parte, si el objetivo es sintetizar un estado de situación de la antropología en turismo en la actualidad, Hernández-Ramírez y otros (2015) señalan que se ha pasado de una casi inexistencia a una progresiva institucionalización. No obstante, especifica que la antropología del turismo tuvo un proceso de desarrollo tardío, que se consolida a finales de los ‘90 y que, pese a dichos avances, permanece 
todavía en un rol marginal dentro del campo científico del turismo. Desde este lugar, las unidades de análisis más estudiadas en relación al turismo son: el patrimonio cultural, las temáticas de desarrollo turístico, representaciones, medio ambiente y las poblaciones originarias y locales receptoras. $\mathrm{Al}$ mismo tiempo, y tomando algunos conceptos de Ortiz (2004) podríamos concluir que los estudios en turismo caracterizan por estar inmersos en al menos tres tensiones conceptuales. Por un lado convive en la tensión que tiende al culturalismo, en tanto aquel enfoque que analiza un fenómeno o proceso exclusivamente desde el punto de vista cultural, (dejando de lado la economía, política, tecnología, etc.) y donde la cultura es caracterizada en función de una coherencia y homogeneidad interna. Por otro, una tensión que emparentada (y hasta superpuesta) a la anterior tiende a un enfoque relativista o esencializante donde cada diferencia es vista como un mundo autónomo, una isla, regida por reglas propias, discretas. Y, finalmente, se agrega una economicista. Es decir, circunscribir la cultura a aquellos referentes que son demandados (o puedan ser) demandados por el turista en tanto adquieran un valor de uso o de cambio.

Para Coronado, (2015) la antropología se ha mantenido renuente a priorizar el estudio del turismo en sí. Si bien se reconoce su creciente importancia, la presencia antropológica ha sido marginal y sesgada. Este punto es retomado por Pinto (2015) para el contexto de la antropología turística brasilera donde reconoce que entre las causas de dicha marginalidad es que se sostiene que el turismo aun es entendido como poco serio, frívolo por el hecho es estar vinculado al ocio, al placer.

No obstante, pese cierta a predominancia de enfoques tradicionalistas al momento de analizar la cultura, no es menor destacar el crecimiento de abordajes que consideran la "otredad" desde nuevos paradigmas y que se caracterizan por reaccionar a la invisibilidad y a otras formas de dominación (Valdés et. al.2011). Entre ellas, y a los efectos de destacar una, sobresale el feminismo cuya impronta le otorga a la dimensión espacial el involucramiento del cuerpo: la "micro-política". Los estudios de género, "genderización" o teorías "queer" ponen de manifiesto que las conexiones entre los procesos globales y locales no son abstractas sino que están siempre corporeizadas y situadas en algún lugar concreto. Cabezas González (2013) dirá la necesidad de incorporar a personas de carne y hueso a los paisajes y mapas de las relaciones de poder. En virtud de ello, la geografía política feminista pone de manifiesto al cuerpo como una escala espacial de análisis para la estructuración de lo político, un espacio tanto de resistencia como de opresión. Pero el punto es que lo que se abren no solo son otras formas de lucha y resistencia sino que, además, analíticamente permite reflexionar sobre la porosidad de las fronteras y movilidad. Esta autora, con influencia foucaultiana, incorporará la biopolítica, es decir el poder de controlar las vidas, los cuerpos y generar subjetividades a partir de la producción de identidades de forma menos evidente pero que no por ello ajena o exenta de violencia

En este marco, es que se entiende que coexiste una lectura ambivalente en términos de "sobre" y "contra" cultura, y sin pretender recaer en una lógica binaria, la propuesta es tomar la dualidad en la unidad. Es decir, tal como sostiene Ortner (2005) reconocer los peligros muy "reales" de la cultura cuando se la pone en juego para esencializar y demonizar a grupos enteros de personas pero, al mismo tiempo, como un concepto que posee un valor político crítico, para entender el poder como los recursos de quienes carecen de él. En tal sentido, "la cultura" puede ser entendida no como inherentemente conservadora o peligrosa, sino como un concepto flexible y, como tal, requiere de problematizaciones en torno a sus usos pero a partir de su reflexión en el orden ontológico y epistemológico. Por otra parte, tomando los aportes de la idea de "diferencia" adquiere un carácter ambivalente. Es necesaria para la producción de significados, la formación de lenguaje, identidades sociales e incluso de sí mismo como sujeto sexuado pero, al mismo tiempo, puede ser amenazante en tanto que acarrea sentimientos negativos, hostilidad, agresión hacia el otro, es "amenazante" (Hall, 2010:. El uso turístico del patrimonio, en este sentido, puede ser entendido como una estrategia política que produce o fortalece la dominación (y, con ello la exclusión) de ciertos grupos culturales pero también como una herramienta de reivindicación identitaria o, al menos, fortalecer los valores culturales que distinguen a grupos sociales.

La práctica turística no es única ni homogénea, es también multifacética y, como tal, es tensional y disputada. Conlleva, en esos términos, múltiples caras que pueden ir desde la funcionalidad o agencia de mercantilización más despiadada de elementos y personas pero, también, una estrategia para alcanzar objetivos económicos bajo formas no tradicionales o, también, de objetivos políticos, como la inclusión de la mujer o el reconocimiento de grupos históricamente excluidos. Tal como sugiere Lagunas Arias (2010) las interacciones entre los turistas y los locales comprenden mucho más que una simple transacción de bienes y dinero, también incluyen el intercambio de expectativas, estereotipos y expresiones de etnicidad y cultura.

Por otra parte, y si bien se puede reconocer las asimetrías de poder que existen entre los turistas y los visitados, aún persiste una desproporcionada atención prestada a los impactos negativos experimentados 
por parte de los lugareños. Como se dijo anteriormente, Salazar (2006) esto refleja cierto sesgo etnocéntrico en la investigación en tanto se tiende a considerar a los anfitriones en términos de personas pasivas e impotentes. Más precisamente puede implicar, por ejemplo, la imposibilidad de ver estrategias tales como el turismo en tanto vehículo de empoderador de la autorepresentación. En este marco político de entendimiento, Fuller (2015) propone dar el giro del debate para superar la tendencia a recaer en la dualidad auténtico/ inauténtico, verdadero/falso, realidad/ espectáculo y entender que la autenticidad no es una cualidad inherente a un rasgo o fenómeno cultural. En la práctica, la autenticidad se ha convertido en un juego de poder, de disputa, entre diversos actores sobre quién tiene la autoridad para decidir. Más concretamente, y en base a un caso de un pueblo en Cuzco (Perú), grafica que la disputa sobre la autenticidad no solo moviliza recursos turísticos sino que es una arena donde se definen y redefinen las cuotas de poder de los diferentes sectores sociales.

De este modo, y con el objeto de superar la lógica binaria o dicotomía valorativa (positivo o negativo) que predominaba en la antropología del turismo durante los '70, Francesch Díaz (2016:11) afirma:

"Ahora sabemos que no solo hay impactos y sociedades pasivas, las que reciben los impactos, que alzan las manos con impotencia y experimentan procesos de aculturación no deseados. Ahora sabemos que los actores en liza negocian, eluden, asimilan, sufren o modifican los procesos de impacto y aculturación; sabemos también que los impactos tienen no solo receptores, sino agentes de impacto, los turistas, y que estos tampoco son robots, "tontos culturales", el "idiota que viaja" (Urbain 1993)."

En este marco, se puede vislumbrar en el inicio del siglo XXI que aún permanecen, quizás más desvanecidas, tendencias esencializantes, especialmente por fuera del campo antropológico, y desde el campo interdisciplinar, un desplazamiento de la centralidad de los análisis de lo discreto hacia una preocupación por el continuo. No necesariamente quizás en un progresivo "abandono" de los enfoques sistémicos, tal como sostiene Nogués Pedregal (2009), pero si al menos un cuestionamiento y la necesidad de relocalizar y ampliar los debates de poder, conflicto y frontera. Lo que sí está claro para el autor es existe una tendencia al desdibujamiento espacio-temporal entre nativos y turistas, y la conceptualización de "nuevos" actores, como son los casos de los residentes 'extranjeros' o inmigrantes 'laborales' o, incluso, las nuevas modalidades turísticas de difícil encuadramiento. Estos cambios han llevado a que la diferenciación entre el tiempo libre, el tiempo obligado y el tiempo de trabajo, que solía ser el sustento del análisis sociológicos de décadas anteriores, haya perdido su validez a partir de las superposiciones frecuentes entre los tres tipos de tiempos (Hiernaux, 2006). Ese turista no es solamente un viajero extraño que genera cambios, sino que a partir de ahora puede ser construido y reconstruido a partir de identidades hibridas que pone en juego múltiples fronteras. Por su parte, el anfitrión, no es un mero sujeto pasible (y pasivo) de ser "aculturado" sino que está constituido por son múltiples agentes que disputan una formación discursiva, más o menos evidente, de su identidad, costumbres y tradiciones. Lo que está en juego, de forma y estrategias distintas, con recursos diferentes, es la política.

\section{Conclusiones}

Si hay un tema que el presente trabajo intentó poner en agenda de reflexión es la necesidad de pensar y repensar en torno a la constitución y consolidación de tres campos diferentes: la antropología, los estudios culturales y los turísticos. Claramente, de lo antes descrito, difícilmente se pueda extraer un cierre hermético sino que, por el contrario, se espera que abran nuevas preguntas que instan a seguir problematizando, construyendo y deconstruyendo. Para ello se tomó como estrategia la segmentación de dos momentos dentro de la estructuración del campo antropológico en turismo. Contextos epocales que no solo se entienden en un sentido progresivo y lineal sino como inestables discusiones ontológicas (qué es el turismo y la cultura) y epistemológicas (cómo se los puede conocer). Es decir, no solo se provee de un contexto e historicidad, sino también en reflexionar sobre la capacidad performativa y discursiva del conocimiento, vista en las cosas, los cuerpos, en el territorio. De esta manera repensar el posicionamiento frente a las teorías más generales cobra una importancia notable, sobre todo porque son dichos premisas las que luego actuará en el establecimiento de unidades observables, métodos de validación, de límites, regularidades empíricas y, por defecto, formas de intervenir la realidad social.

Dicho esto, lo que sí se puede afirmar es que este campo joven (al menos en su institucionalización), abre unidades antes impensadas, donde las discusiones actuales no solo alertan de los peligros que acarreó y sigue acarreando (tanto el turismo como el debate cultural) sino para dar lugar a nuevas 
fronteras, entre nuevos y confusos "yo(s)" y "otros". Los estudios en turismo evidencian la necesidad seguir incorporando y profundizando los Estudios Culturales, de superar el pasivismo intelectual que se les adjudicó a las comunidades locales así como el juzgamiento hacia el visitante, la necesidad de recomponer las tramas de relaciones en virtud del poder y el contexto o la misma necesidad de trascender las disciplinas a partir de abordajes transdisciplinares. Asimismo, y a la inversa, el turismo abre terreno para el análisis desde los nuevos enfoques críticos de la antropología o, incluso, de los mismos Estudios Culturales. Si hay una dimensión de la que se pueden hacer "eco" los estudios turísticos no son las características compartidas que hizo hincapié históricamente el culturalismo, sino los puntos de contactos, los límites, las zonas de fricción, los intersticios. Si se toman los aportes de Barth (1976), las distinciones no dependen de la ausencia de interacción, sino que generalmente son el fundamento mismo. Es desde este lugar, desde la fluidez, el hibridismo y el contacto entre "otros" culturales, de donde se sostiene que teórica y empíricamente se abren nuevos horizontes. Existe, por tanto, una relación simbiótica, entendiendo que los debates antropológicos no solo pueden enriquecer y complejizar el abordaje teórico y empírico de los estudios en el turismo sino que, también, a la inversa, estos últimos pueden reorientar y complejizar sus conceptualizaciones y aplicaciones.

\section{Bibliografía}

Abu-Lughod, L.

1991. Writing against culture, Andamios: Revista de Investigacion Social, 9(19): 466-479.

Barreto, M.

2007. Turismo y cultura. Relaciones, contradicciones y expectativas, ACA y PASOS, Tenerife, España: 1-176. Barretto, M. y Otamendi, A.

2015. Antropología y Turismo en "Los Países del Plata" (Argentina y Uruguay); PASOS. Revista de

Turismo y Patrimonio Cultural, 13(2): 283-294.

Barth, F.

1976. Los grupos étnicos y sus fronteras, Fondo de cultura económica, 197(6): 1-49.

Brumann, C.

1999. Writing for culture: Why a successful concept should not be discarded, Current anthropology, (40),

Supplement: special issue: culture. A second chance?: S1-S27.

Cabezas González, A.

2013. Cuerpos que importan en las geometrías del poder; en Cairo Carou, H. et. al., XV Encuentro de Latinoamericanistas Españoles, Trama editorial, CEEIB, Nov 2012, Madrid, España: 841-845.

Comparato, G.

2017. Epistemología del Turismo. Entre luces y sombras, Caderno virtual de turismo, en prensa: pp. 1-24. Coronado, G.

2015. De la curiosidad a la prioridad: el lugar del turismo en la antropología, Desacatos. Revista de Antropología Social, № 47: 90-97.

Dos Santos, R. J,

2005. Antropología, comunicación y turismo. La mediación cultural en la construcción del espacio turístico de una comunidad de pescadores en Laguna, SC, Brasil, Estudios y Perspectivas en Turismo, 14: 293-313.

Follari, R.

2003. Los estudios culturales como teorías débiles, Ponencia al Congreso de la LASA (Latin American Studies Association), realizado en Dallas, Texas: 1-17.

Francesch Díaz, A.

2016. Antropólogos, turistas, confusiones y reflexiones, PASOS. Revista de Turismo y Patrimonio Cultural, 14(1): 11-21.

Fuller, N.

2015. El debate sobre la autenticidad en la antropología del turismo; Revista de Antropología Experimental, $\mathrm{N}^{\circ} 15$, monográfico turismo, texto 8, Universidad de Jaén: 101-108.

Geertz, C.

2003. La interpretación de las culturas, Gedisa editorial: 1-41.

Hall, S.

2000. Estudios culturales y sus legados teóricos, Voces y culturas, 16; Traducción por Carmelo Arias Pérez: 9-27. 
2010. El espectáculo del “otro", en Restrepo, E. ed., Sin garantías: trayectorias y problemáticas en estudios culturales, Corporación Editorial Nacional, Ecuador, 2013: 431-457.

Hiernaux, N.

2006. Geografía del turismo, en Lindón, A. y Hiernaux, N., Tratado de Geografía humana, Anthropos Editorial, UAM, Iztapalapa, México: 401-432.

Jafari, J.

1994. La cientifización del turismo; Estudios y Perspectivas en Turismo;3 (1): 7-36.

2005. El turismo como disciplina científica; Política y sociedad, 42(1): 39-56.

Lagunas Arias, D.

2010. Antropología, cultura y turismo (y un ejemplo), en Fournier, P. y López Aguilar, F. coord., Patrimonio, identidad y complejidad social: enfoques interdisciplinarios, México D. F., ENAH: 379-394.

Nogués Pedregal, A. M.

2009. Genealogía de la difícil relación entre antropología social y turismo, PASOS. Revista de Turismo y Patrimonio Cultural; 7 (1): 43-56.

Ortiz, R.

2004. Estudios culturales, fronteras y traspasos. Una perspectiva desde Brasil, en Taquigrafiando lo social, Siglo XXI, Buenos Aires: 190-202.

Ortner, S.

1999. The Fate of "Culture" Geertz and Beyond; University of California Press: 1-11.

2005. Geertz, subjetividad y conciencia posmoderna, Etnografías contemporáneas, 1(1): 25-54.

Pagès, G.

2012. Una aproximación a los estudios culturales latinoamericanos; en Serrano, E. coord., De la tierra al cielo: Líneas recientes de investigación en historia moderna, I Encuentro de Jóvenes Investigadores, Zaragoza: 279-298.

Pereriro, $\mathrm{X}$.

2013. Los efectos del turismo en las culturas indígenas de América Latina, Revista Española de Antropología Americana, 46(1): 155-174.

Pinto, R.

2015. O turismo na tradição antropológica brasileira, PASOS. Revista de Turismo y Patrimonio Cultural; 13, (2): 295-303.

Restrepo, E.

2012. Antropología y estudios culturales: disputas y confluencias desde la periferia, Editorial Siglo Veintiuno; Buenos Aires.

Salazar, N.

2006. Antropología del turismo en países en desarrollo: análisis crítico de las culturas, poderes e identidades generados por el turismo; Tabula rasa, 5: 99-128.

2013. Imagineering otherness: Anthropological legacies in contemporary tourism; Anthropological Quarterly, 86(3): 669-696.

Santana-Talavera, A.

2015. Turismo, incursiones interdisciplinares desde la antropología social; Estudios y Perspectivas en Turismo; Edición Especial "25ªniversario": 83-99.

Valdés, E. et. al.

2011. Visibilizar el paisaje del miedo. Una aproximación desde las espacialidades y temporalidades; Anuario de la Escuela de Historia Virtual, Año 2 - N²2: 76-92.

Valencia, H. I.

2011. Antropología y estudios culturales: entre el teorizar de la política y la politización de la teoría; Tabula Rasa; (15), julio-diciembre: 95-111

Wright, S.

2004. La politización de la cultura; en Boivin M. et. al., Constructores de Otredad. Una introducción a la antropología social y cultural; Buenos Aires: Eudeba: 128-141.

Recibido:

$01 / 08 / 2017$

Reenviado:

$09 / 06 / 2018$

Aceptado:

$10 / 06 / 2018$

Sometido a evaluación por pares anónimos 